\title{
Fuel Flexibility Study of a Compression Ignition Engine at High Loads
}

\author{
Abdullah S. AlRamadan, Moez Ben Houidi, Gustav Nyrenstedt and Bengt Johansson \\ King Abdullah University of Science and Technology
}

Copyright (C) 2019 SAE Japan and Copyright @ 2019 SAE International

\begin{abstract}
Engine experiments were performed on a singlecylinder heavy-duty engine at relatively high loads to investigate the regions where the combustion characteristics are unchanged regardless of the fuel octane number. Primary Reference Fuels (PRFs) and three different commercial fuels with RON values ranging from 0 to 100 were tested in this study. A sweep of net indicated mean effective pressure (IMEP Net of 5 to 20 bar, absolute intake pressure of 1.5 to 2.8 bar, exhaust gas recirculation (EGR) of 0 to $40 \%$, and fuel injection pressure of 700 to 1400 bar were performed to investigate the combustion characteristics, ignition delay time, combustion duration, efficiency, and emissions. At the highest load point $\left(\right.$ IMEP $_{\text {Net }}=20$ bar), all the fuels burn as in conventional diesel combustion. Despite the wide range of octane numbers, all fuels had similar ignition delay time, combustion duration, indicated efficiency, and emissions at 10 to 20 bar IMEP Net. It follows that $\mathrm{Cl}$ mode is the only realistic option at high load and pressure points. All fuels showed similar combustion duration and emission levels behavior as a function of EGR. The present study shed light on the load threshold above which the combustion characteristics of fuels are close enough to consider the engine as 'fuel flexible'.
\end{abstract}

\section{INTRODUCTION}

Transportation in its major forms consumes $20 \%$ of the world's primary energy and emits more than $20 \%$ of the global greenhouse gases (GHG) [1-3]. All of the transport technologies are virtually powered by internal combustion (IC) engines ( 99.9\%), from which $95 \%$ of their energy is supplied by petroleum $[4,5]$. Even with the growing population of electrically powered vehicles, which will reduce the transportation energy share of petroleum fuels, future projections anticipate an increase in the demand for liquid fuels by $33 \%$ in 2040 $[6,7]$.

The increase in liquid hydrocarbons demand is directed towards diesel and jet fuels because of factors related to electrification, efficiency gains, population growth, and urbanization [7, 8]. Further discussion about these factors are presented in [9, 10]. As refineries attempt to make up for the imbalance in diesel+jet fuel versus gasoline without major infrastructural changes, the availability of less processed gasoline with low octane quality increases [11]. This triggered Kalghatgi's interest in utilizing these potential 'homeless hydrocarbons' in Gasoline Compression Ignition $(\mathrm{GCl})$ where low octane gasoline are the optimum fuels for such combustion mode [1215]. This paper is part of an initiative to attain an engine configuration with enhanced flexibility in terms of its appetite to burn any fuel. This will pave the way to utilize less processed fuels with reduced cost and environmental impact.

There are various studies that investigated the engine capability to adapt to fuels with different octane qualities at certain combustion modes. Christensen et al. [16] established multi-fuel capability for a Homogeneous Charge Compression Ignition $(\mathrm{HCCl})$ engine to achieve optimum combustion phasing. The enabler for such fuel flexibility is the variable compression ratio system incorporated with the engine to control the start of ignition. The engine flexibility at Partially Premixed Combustion (PPC) mode to wide range of fuels was analyzed by Manente et al. [15]. Nine fuels with varying octane numbers were tested in load sweep of 5 to 26 bar IMEP gross. The conclusion derived was that the engine is fuel flexible for all the fuels except for high octane number fuels $(R O N>70)$ where auto-ignition became a problem.

Similar to the focus of this work, there are multiple studies that explored the combustion characteristics of fuels with different octane qualities at high loads. Wang et al. [17] studied the burning of different fuels with RON 70 and diesel at PPC mode. They reported that it is challenging to maintain PPC mode with low octane quality at high loads due to short ignition delay times. In addition, Paz et al. [18] compared the burning regime of diesel and gasoline at high load $\left(\right.$ IMEP $_{\text {gross }}=$ 20 bar). The burning at this point is mainly diffusion driven for both fuels with a minor difference in ignition delay time between gasoline and diesel of 2 CAD. Only slight deviations in combustion characteristics at high EGR rates were reported. Understanding the governing combustion regimes at extreme conditions is valuable for advanced IC engine concepts. An 
example to that is the double compression expansion engine concept where its combustion chamber can potentially operate at 300 bar [19-22]. It is worthwhile to know if the combustion characteristics are invariant regardless of the fuel fed to the system.

This study aims to investigate the engine load range where the combustion characteristics are similar regardless of the octane number of the fuel used. This helps to characterize the flexibility of the engine to operate with wide range of fuels. Primary Reference Fuels (PRFs) and three different commercial fuels with RON values that range from 0 to 100 were tested at

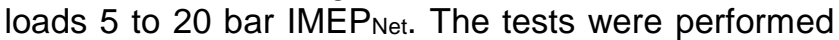
maintaining the combustion phasing at an optimum value. To further assess the effect of octane number on the ignition delay time, several tests were performed at density levels similar to previous cases and at fixed start of injection (SOI). Finally, the effect of exhaust gas recirculation (EGR) is investigated at the same load range.

\section{EXPERIMENTAL SETUP}

Experiments were performed on a single-cylinder engine test bench at King Abdullah University of Science and Technology (KAUST). A Volvo D13C500 6 -cylinder engine was modified by deactivating five cylinders and disengaging their gas exchange system. Fig. 1 shows a schematic of the experimental setup used in this study. The detailed specifications of the engine are presented in Table 1.

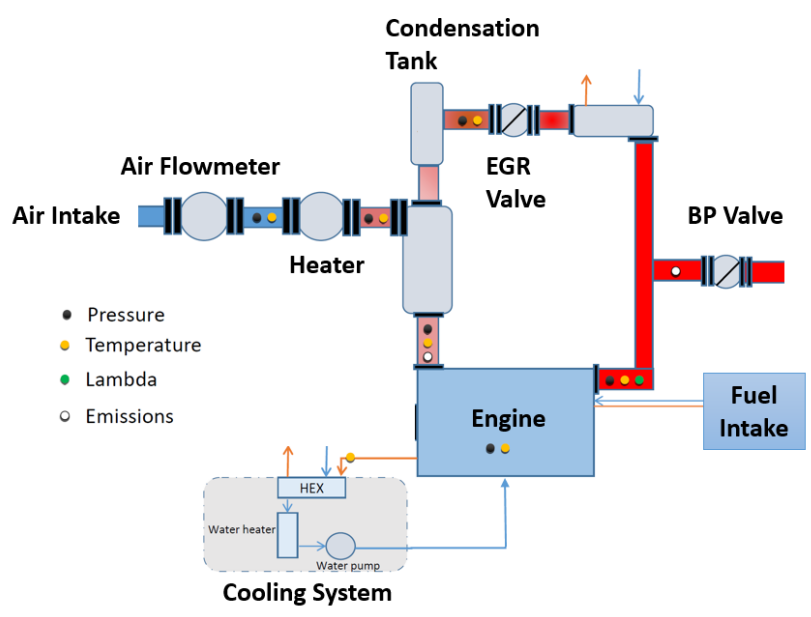

Fig. 1. Schematic of the single-cylinder Volvo engine setup

Table 1. Volvo single-cylinder $\mathrm{Cl}$ engine specifications

\begin{tabular}{|l|l|}
\hline Engine Type & $\begin{array}{l}\text { Single-cylinder Volvo D13F, 4 } \\
\text { stroke }\end{array}$ \\
\hline Compression Ratio & $17: 1$ \\
\hline Bore & $131 \mathrm{~mm}$ \\
\hline Stroke & $158 \mathrm{~mm}$ \\
\hline Connecting Rod & $255 \mathrm{~mm}$ \\
\hline Displacement Volume & $2.13 \mathrm{~L}$ \\
\hline Fuel Injection System & $\begin{array}{l}\text { Common Rail, Delphi F2E, } \\
\mathrm{P}_{\max }=2700 \text { bar }\end{array}$ \\
\hline Max Cylind. Pressure & $200 \mathrm{bar}$ \\
\hline $\begin{array}{l}\text { Max Intake Boost } \\
\text { Pressure (absolute) }\end{array}$ & $3 \mathrm{bar}$ \\
\hline $\begin{array}{l}\text { Max Intake } \\
\text { Temperature }\end{array}$ & $120^{\circ} \mathrm{C}$ \\
\hline
\end{tabular}

\begin{tabular}{|l|l|}
\hline Maximum Speed & $2400 \mathrm{rpm}$ \\
\hline Swirl Ratio & 0 \\
\hline Valve Configuration & $\mathrm{SOHC}, 4$ valves per cylinder \\
\hline Coolant Temperature & $80^{\circ} \mathrm{C}$ \\
\hline Lubricant Temperature & $80^{\circ} \mathrm{C}$ \\
\hline
\end{tabular}

Air is fed to the engine intake using external compressed air supply and was controlled using a pneumatic valve. The regulated air supply has the capability of providing air to the engine intake at a pressure of 3 bar absolute. The intake system is coupled with an air heater that can heat the intake charge up to $120^{\circ} \mathrm{C}$. A back-pressure valve is mounted in the exhaust line to provide the capability of pressurizing the exhaust. This enables creating positive pressure change between the exhaust and intake that simulates the operation of turbocharger. The amount of exhaust gas recirculation (EGR) fed to the intake, which is cooled using a heat exchanger, is controlled through a combination of the back pressure and the EGR valves. Pressure and temperature sensors were mounted at the intake, exhaust and EGR lines to monitor and control the flow conditions. The incylinder pressure of the engine was measured using a Kistler 7061C M14 piezo-electric pressure transducer mounted on the cylinder head and a Kistler 1721 amplifier. The data was sampled with a resolution of 0.2 CAD. HORIBA MEXA-ONE-RS Motor Exhaust Gas Analyzer was connected to the exhaust line for detailed exhaust measurements of $\mathrm{CO}, \mathrm{CO}_{2}, \mathrm{O}_{2}, \mathrm{CH}_{4}$, $\mathrm{NO}, \mathrm{NO}_{2}$, and $\mathrm{EGR} \mathrm{CO}_{2}$. Soot concentration was measured using $\mathrm{AVL}$ micro soot sensor at a resolution of $0.01 \mu \mathrm{g} / \mathrm{m}^{3}$.

The fuel injection system is based on the Delphi F2E concept [23]. A pumping injector is used to pressurize the fuel where the rail pressure depended on load. The injector is composed of seven holes with a nominal diameter of $225 \mu \mathrm{m}$. To avoid fuel evaporation, the temperature of the fuel return is regulated by external heat exchanger. Throughout the experiments, data was recorded for 400 cycles in the fired cases and 100 cycles in the motored cases ensuring that the coefficient of variance was lower than $5 \%$ for the IMEP.

\section{FUELS PROPERTIES AND COMPOSITION}

To isolate the octane number effect from other fuel's physical properties, most of the experiments were performed with Primary Reference Fuels (PRFs). The standard test methods for measuring the research octane number (RON) [24] and motor octane number (MON) [25] are based on comparing the auto-ignition tendency of fuels with PRFs. Hence, a fuel with RON or MON of 70 has the same auto-ignition behavior as PRF70, which is a blend of $70 \%$ isooctane and $30 \% \mathrm{n}$ heptane by volume.

Seven fuels have been tested: four different PRFs and three commercial fuels. The tested PRFs are PRFO (nheptane), PRF30, PRF70, and PRF100 (isooctane). The studied commercial hydrocarbons are diesel supplied by Coryton, gasoline supplied by Haltermann, and one of the Fuels for Advanced Combustion Engines (FACE) supplied by Coordinating Research Council, namely FACE I [26]. The suitability of the 
commercial fuels tested herein covers various combustion regimes. Coryton Diesel with its high cetane number of 53.8 is appropriate for $\mathrm{Cl}$ combustion, Haltermann gasoline with RON 91 is designed for SI combustion, and FACE I representative of naphtha fuel with its low RON of 70.0 can be a promising fuel for partially premixed combustion (PPC) [13-15]. Table 2 summarizes the key properties of the examined commercial fuels.

Table 2. Fuel properties and composition of tested commercial fuels

\begin{tabular}{|l|l|l|l|}
\hline Property & Diesel & FACE I & Gasoline \\
\hline RON & - & 70.0 & 91.0 \\
\hline MON & - & 69.5 & 83.4 \\
\hline $\begin{array}{l}\text { Cetane } \\
\text { Number }\end{array}$ & 53.8 & - & 41.92 \\
\hline $\begin{array}{l}\text { Net calorific } \\
\text { value (MJ/kg) }\end{array}$ & 43.21 & 44.72 & 1.98 \\
\hline H/C ratio & 1.78 & 2.25 & 26.5 \\
\hline $\begin{array}{l}\text { Aromatics } \\
\text { (\%Wt) }\end{array}$ & 25.9 & 1.2 & 10 \\
\hline $\begin{array}{l}\text { Ethanol } \\
(\% \text { Vol) }\end{array}$ & 0 & 0 & \\
\hline
\end{tabular}

\section{TEST PROCEDURE}

\section{EFFECT OF ENGINE LOAD}

The first part of this study aims to investigate the combustion characteristics, at different loads, with different fuels. Load sweeps are performed by either fixing the combustion phasing or the start of injection. Detailed test conditions are described below.

\section{Constant Combustion Phasing (CA50)}

In this part of the study, load sweep was performed for PRF0, PRF30, PRF70, and PRF100. The engine loads, which were explored for each fuel, are net indicated mean effective pressures (IMEP Net $_{\text {) }}$ of $5,10,15$, and 20 bar. For all the loading points, the start of injection was adapted to achieve constant combustion phasing of $\mathrm{CA} 50=5 \mathrm{CAD}$ aTDC, where CA50 is the CAD at which $50 \%$ of the heat is released. According to Leermakers et al. [27] who explored the optimum CA50 for different octane number fuels to achieve the highest gross indicated efficiency, CA50 of 5 CAD aTDC is the best averaged combustion phasing for $\mathrm{Cl}$ combustion. For the highest load condition, the CA50 was switched to 10 CAD aTDC to keep the peak pressure at acceptable limits. Lambda was maintained for IMEP $_{\text {Net }}$ of 5 and 10 bar at 3.5 but then fuel enrichment was needed to attain higher loads.

The effect of intake charge temperature on fuels' combustion characteristics was isolated in this study by maintaining its value at $20^{\circ} \mathrm{C}$. The temperature selection mimics the operation of perfect intercooler. The low temperature value represents the worst case in terms of differentiating the behavior of fuels. At temperatures beyond $20^{\circ} \mathrm{C}$, the variation of combustion characteristics between fuels will reduce. The intake pressure was altered with load as seen in
Table 3. These intake pressures correspond to peak motored pressures of 70, 120, and 140 bar, respectively. The fuel rail pressure was varied depending on the boost level. The engine speed was fixed at $1200 \mathrm{rpm}$. Exhaust pressure was kept at a level of 0.2 bar higher than the intake pressure. The purpose of the induced exhaust pressure was to simulate the pressure drop that occurs across the turbocharger for boosted engines. A summary of the experimental conditions for the constant combustion phasing load sweep is shown in Table 3.

Table 3. Test conditions of the load sweep analysis at constant combustion phasing

\begin{tabular}{|c|c|c|c|c|}
\hline IMEP $_{\text {Net }}[\mathrm{bar}]$ & 5 & 10 & 15 & 20 \\
\hline Fuels Tested & \multicolumn{4}{|c|}{$\begin{array}{l}\text { PRF0, PRF30, PRF70, and } \\
\text { PRF100 }\end{array}$} \\
\hline Pintake [bar] & 1.5 & 2.5 & 2.5 & 2.8 \\
\hline $\mathrm{T}_{\text {intake }}\left[{ }^{\circ} \mathrm{C}\right]$ & \multicolumn{4}{|l|}{20} \\
\hline CA50 [aTDC] & 5 & 5 & 5 & 10 \\
\hline Rail pressure [bar] & 700 & 1200 & 1200 & 1400 \\
\hline Lambda & 3.5 & 3.5 & 2.1 & 1.8 \\
\hline Engine speed [rpm] & \multicolumn{4}{|c|}{1200} \\
\hline Pexhaust $-P_{\text {intake }}[\mathrm{bar}]$ & \multicolumn{4}{|c|}{$\sim 0.2$} \\
\hline
\end{tabular}

\section{Constant Start of Injection (SOI)}

The constant combustion phasing analysis is representative of typical engine operations where the start of injection (SOI) is adapted to achieve the optimum combustion phasing. However, this creates a mismatch of pressure and temperature conditions for different octane number fuels when they are fed to the combustion chamber. Hence, in order to analyze fuels with different octane ratings at consistent cylinder conditions, load sweep was performed by fixing the SOI. The fuels analyzed in this phase of the study were the four PRFs tested in the constant combustion phasing analysis with the addition of three commercial hydrocarbons, namely diesel, FACE I, and gasoline.

Lambda was maintained for all the cases at 6 , which creates slightly moderate load points compared to the combustion phasing analysis. Three load points for all the fuels were analyzed of IMEP $\mathrm{Net}_{\mathrm{N}}=3,5$, and 6 bar, which corresponds to intake pressures of 1.5, 2.0, and 2.5 bar, respectively. The rail pressure was increased with load elevation. The speed of the engine was fixed at $1200 \mathrm{rpm}$. The intake temperature was again kept at $20^{\circ} \mathrm{C}$ to discard the temperature effect. The difference between the pressure of exhaust and intake was again kept at around 0.2 bar to replicate the pressure drop in a turbocharger. Table 4 summarizes the conditions of constant SOI analysis.

Table 4. Test conditions of the load sweep analysis at constant SOI

\begin{tabular}{|l|l|l|l|}
\hline Pintake [bar] & 1.5 & 2.0 & 2.5 \\
\hline Fuels Tested & \multicolumn{3}{|l|}{$\begin{array}{l}\text { PRF0, PRF30, PRF70, PRF100, } \\
\text { Diesel, FACE I, and Gasoline }\end{array}$} \\
\hline IMEP $_{\text {Net }}[$ bar] & 3 & 5 & 6 \\
\hline SOI [CAD bTDC] & 8 & 1000 & 1200 \\
\hline Rail pressure [bar] & 700 & 6 & \\
\hline Lambda & 20 & \multicolumn{3}{|l}{} \\
\hline$\left.T_{\text {intake }}{ }^{\circ} \mathrm{C}\right]$ & \multicolumn{4}{|l|}{} \\
\hline
\end{tabular}


\begin{tabular}{|l|l}
\hline Engine speed [rpm] & 1200 \\
\hline
\end{tabular}

Pexhaust - Pintake $_{\text {[bar }]} \quad \sim 0.2$

\section{EFFECT OF EXHAUST GAS RECIRCULATION} (EGR)

Exhaust gas recirculation (EGR) is considered one of the techniques that delivers quality dilution to the combustion chamber. The redirected combustion products, which are cooled by the heat exchanger, decrease the heat transfer losses to the cylinder walls because of temperature reduction. Hence, it is worthwhile to study the sensitivity of fuels to EGR at the examined operational regions. For this section of the experiment, a sweep of EGR was carried out for each condition performed at the constant combustion phasing analysis, highlighted in Table 3 . The EGR effect was tested for only PRF0 (n-heptane) and PRF100 (isooctane) where they represent the boundaries of octane number tests. It should be noted that the SOI and injection duration were fixed to the $0 \%$ EGR case and hence, the CA50 falls beyond the optimized value for the EGR cases presented herein. However, the focus of this analysis is not to optimize the operation but to quantify the variation of the combustion characteristics for different octane number fuels with the EGR introduction.

\section{COMBUSTION PARAMETERS CALCULATIONS}

Parameters are needed to quantify the variation in which fuels release heat. These parameters can be utilized to establish a basis for comparing the combustion characteristics of fuels with different octane ratings at variable load and EGR levels. One important parameter is the time lag between the start of injection (SOI) and the initiation of the auto-ignition event. This parameter is known as the ignition delay time and can determine the level of air/fuel mixing before auto-ignition. In this study, ignition delay time was determined from the heat release code as the difference in crank angle degrees between the SOI and the closest phasing to SOI with positive rate of heat release value.

Another important parameter that characterize the rate of heat release is the combustion duration. It defines the regions where the fuel releases heat and can give an insight about the time available to oxidize some intermediates created during the combustion process. The combustion duration was defined in this study as the difference between the crank angle degrees where $90 \%$ and $10 \%$ of the fuel has burned (CA90-CA10).

\section{RESULTS AND DISCUSSION}

\section{EFFECT OF ENGINE LOAD}

\section{Constant Combustion Phasing (CA50)}

In-cylinder Pressure and RoHR

The in-cylinder pressure trace, rate of heat release (RoHR), and injector signal for all the load cases examined at the constant combustion phasing analysis are shown in Fig. 2, 3, 4, and 5. For the lowest load tested in this study (IMEP ${ }_{\text {Net }}=5$ bar), there is significant variation in the behavior of fuels at different octane ratings. PRFO closely follows the burning regime of typical $\mathrm{Cl}$ mode. The fuel initially releases heat at premixed mode followed by longer diffusion flame that spans beyond the end of injection event. Moving towards PRF30 does not change the combustion characteristic substantially in comparison to PRF0. There is a slight enhancement of mixing identified by the minor rise in the premixed zone peak shown in the RoHR. It is evident that PRF70 has enhanced mixing, which burns more like Partially Premixed Combustion (PPC). PRF70 starts to release heat close to the end of injection. The faster heat release rate of PRF70 causes a slight increase in its peak pressure compared to PRF0 and PRF30. PRF100, with the highest octane quality in the examined palette, has the most air and fuel mixing that spans beyond the end of injection. The enhanced mixing creates more pronounced PPC with sharper RoHR rise and higher peak pressure.

The spread in the fuels' burning regimes shrinks at IMEP $_{\text {Net }}=10$ bar (Fig. 3). PRFO and PRF30 closely follow each other where they have minor premixed zones compared to IMEP Net $_{\text {N }} 5$ bar case and a pronounced diffusion burning. The burning regime of PRF70 converts from PPC to $\mathrm{Cl}$ mode. There is an initial bump in the RoHR representing the premixed combustion, followed by a longer diffusion flame. At this load point, PRF100 maintains its PPC burning feature but with a slight rise of RoHR in its tail highlighting the appearance of a minor diffusion flame. The peak pressure of the examined PRFs at this load point $\left(\right.$ IMEP$_{\text {Net }}=10$ bar $)$ have comparable magnitudes. The slight deviations occur because of the minor mismatch in the motored condition of each PRF.

Further elevation of the load towards $\mathrm{IMEP}_{\mathrm{Net}}=15 \mathrm{bar}$, as illustrated in Fig. 4, diminishes the appearance of PPC burning. The relative magnitude of the premixed zones are maintained for all the PRFs compared to the IMEP Net $=10$ bar case because the initial motored conditions are preserved. However, the region of the RoHR with diffusion type burning is extended for all the PRFs. PRF0, PRF30, and PRF70 follow similar RoHR trends with minor distinction between them. PRF100 has the most apparent premixed combustion but it is incomparable to the extended magnitude of nonpremixed diffusion burning. For all the PRFs tested, the peak in-cylinder pressures are relatively similar in magnitude with the deviation caused by the slight discrepancy in the motored cases.

Fig. 5 shows the highest examined engine load point $\left(\right.$ IMEP $_{\text {Net }}=20$ bar $)$ where no distinction in the incylinder pressure and RoHR between the PRFs is achieved. All the PRFs auto-ignite shortly after the start of injection (SOI) with prevailing diffusion combustion. Out of the PRFs analyzed, PRF100 has the highest premixed zone in the RoHR but it is still small compared to the diffusion zone.

It was demonstrated in this load point that the engine becomes fuel flexible in terms of its octane appetite 
where the in-cylinder pressure trace and RoHR match regardless of the fuel used. In the upcoming subsections, the validity of fuel flexibility at high load will be examined on the combustion characteristics, indicated efficiency, and emissions.

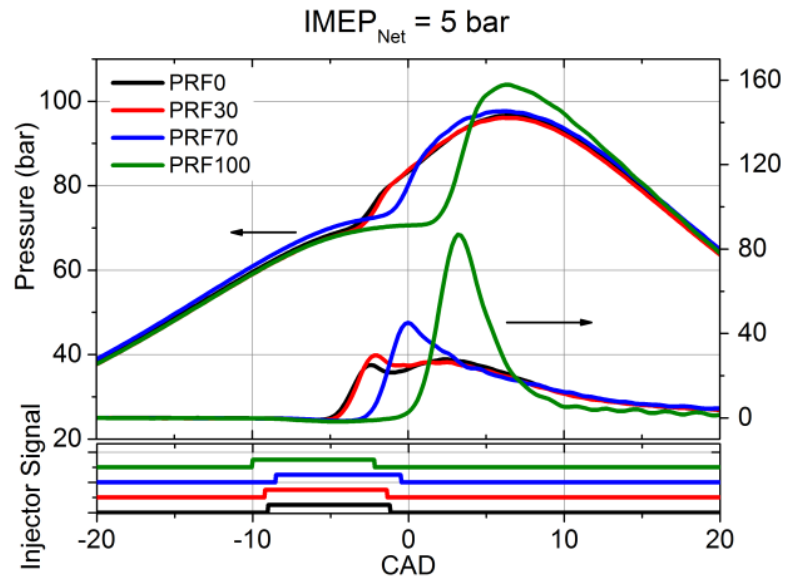

Fig. 2. In-cylinder pressure, rate of heat release, and injector signal of different Primary Reference fuels at $I M E P_{\text {Net }}=5$ bar

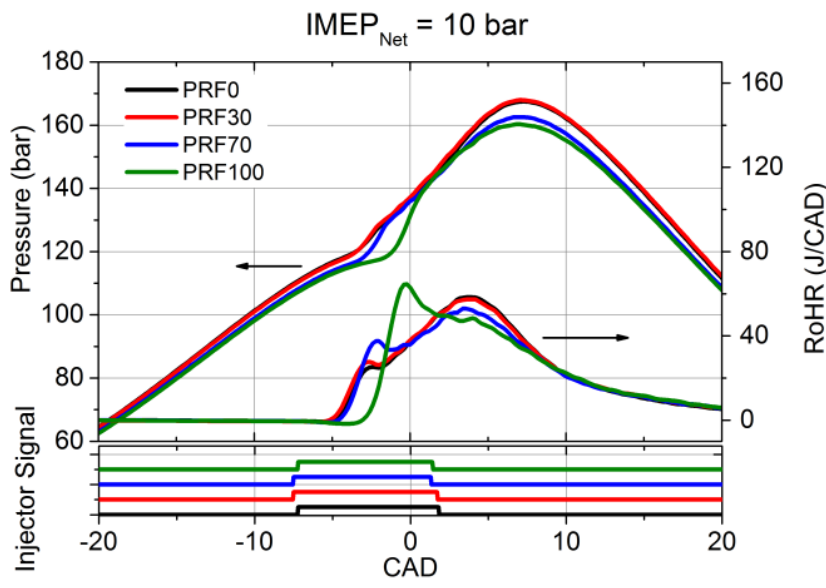

Fig. 3. In-cylinder pressure, rate of heat release, and injector signal of different Primary Reference fuels at $I M E P_{\text {Net }}=10$ bar

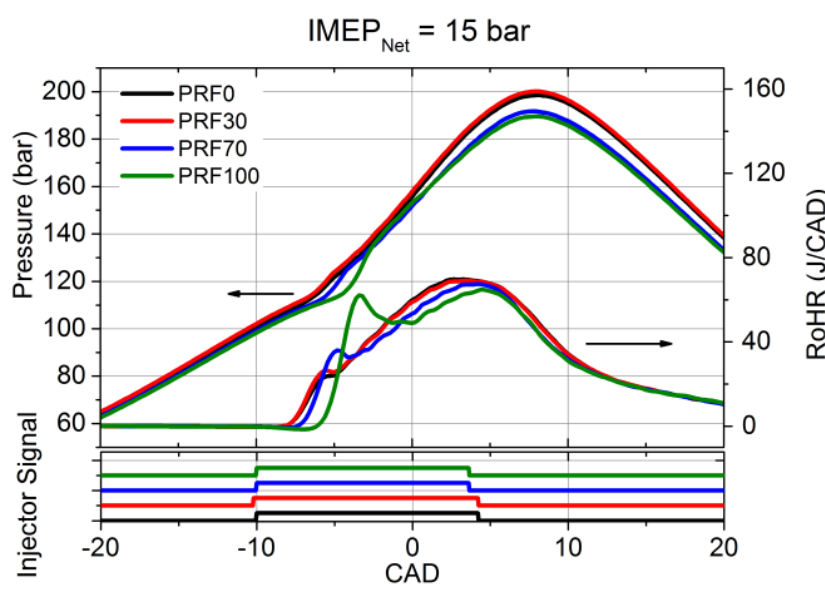

Fig. 4. In-cylinder pressure, rate of heat release, and injector signal of different Primary Reference fuels at $I M E P_{\text {Net }}=15$ bar

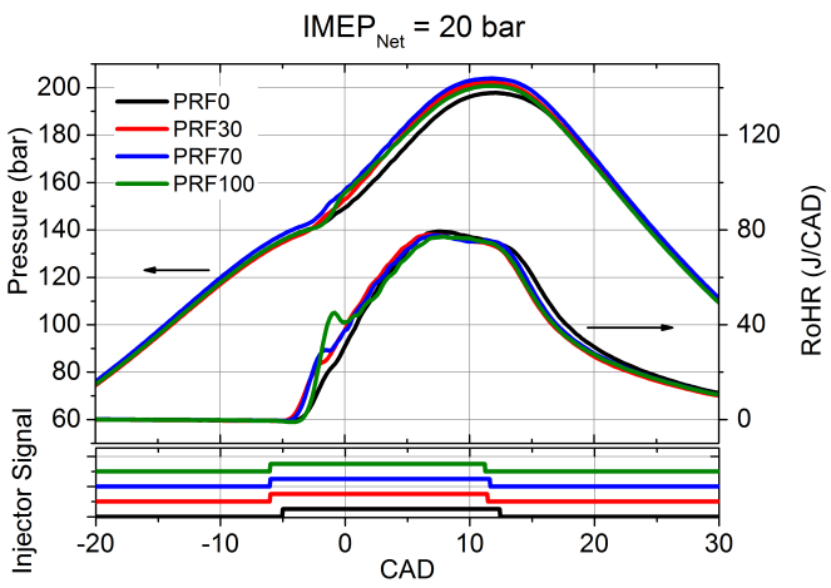

Fig. 5. In-cylinder pressure, rate of heat release, and injector signal of different Primary Reference fuels at $I M E P_{\text {Net }}=20 \mathrm{bar}$

\section{Combustion Characteristics and Efficiency}

One of the common parameters that defines the level of air and fuel mixing is the ignition delay time. Another important parameter for combustion characterization is the combustion duration, which is defined in this study as the difference between CA90 and CA10. Illustrations of the ignition delay time and combustion duration for the cases analyzed in the constant CA50 analysis are shown in Fig. 6.

At IMEP ${ }_{\text {Net }}=5$ bar, there is a clear correlation in the increase in the ignition delay time with higher octane number fuels. The higher ignition delay time enables enhanced mixing for PRF70 and PRF100, from which they appear to burn in PPC mode. In the contrary, the burning of PRF0 and PRF30 are governed by diffusion due to their short ignition delay time. As the mixing duration is extended, the combustion duration is shortened. This occurs because of the increase in the stoichiometric pockets in the combustion chamber.

PRF100 burns at a much shorter duration compared to the other fuels. PRF70 is the only outlier where it has longer combustion duration than expected. This is because of the delayed SOI of PRF70 (shown in Fig. 2) where conditions are higher in terms of temperature and pressure, which reduces the residence time for enhanced mixing.

There is a noticeable decline in the ignition delay time especially for PRF100 going from IMEP Net $=5$ bar to 10 bar. The main contributor to this decline is the elevation of intake pressure. The variation of the ignition delay time between the tested PRFs are within 2 CAD. At these zones, the combustion duration becomes invariant regardless of the fuel's octane number.

Moving towards higher load (IMEP Net $=15$ bar) causes a slight decline in ignition delay time but substantial increase in the combustion duration. It should be noted that motored conditions of IMEP Net $=10$ bar and 15 bar are the same with the main variation is in the injection duration. This explains the consistent increase in the combustion duration for all the PRFs. There is a slight deviation in the ignition delay time of the fuels moving from IMEP $P_{\text {Net }}=10$ bar to 15 bar. The deviations can be 
contributed to the advancement of $\mathrm{SOI}$ in the higher load case (Fig. 3 vs. Fig. 4) to achieve optimum CA50 $=5$ CAD aTDC. This reduces the temperature and pressure at SOI, causing slight divergence of the fuels' auto-ignition tendency.

The variation of ignition delay time and combustion duration between the PRFs collapse at IMEP Net $=20$ bar with minor deviations. Hence, it can be assumed that the combustion characteristics at high loads become diffusion driven regardless of the fuel's octane number. It is once again concluded that the engine is fuel flexible at high loads.

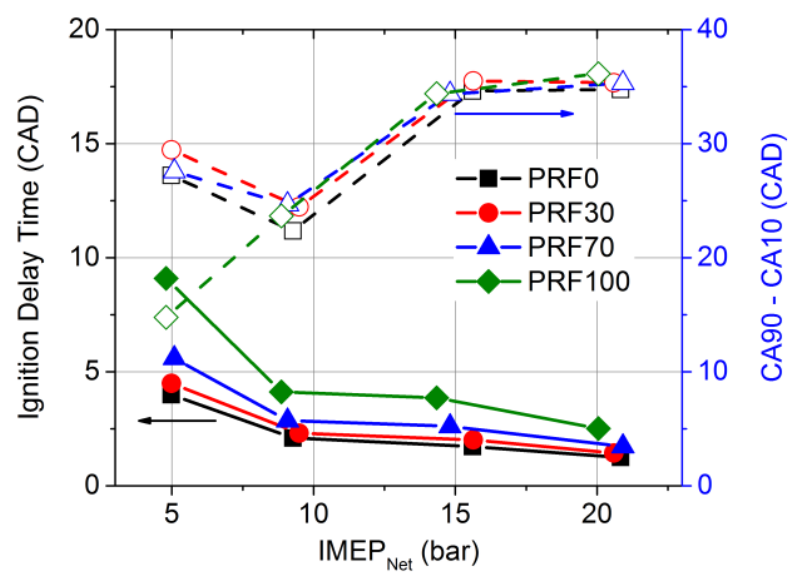

Fig. 6. Ignition delay time and combustion duration (CA90CA10) of PRFs at different engine loads

Gross indicated efficiencies for all the cases tested in the constant CA50 analysis are shown in Fig. 7. Typical IC engines trends are observed with an altered load. The minimum efficiency is found at low loads but then gradually increases as function of load. Beyond a certain intermediate load point, the efficiency starts to drop because of the increase in the heat transfer. At high loads, the combustion phasing has to be retarded to avoid high peak pressures and, hence, an efficiency drop has been reported. This drop is observed at $I_{M E P}{ }_{\text {Net }}=20$ bar, for all the PRFs tested. The indicated efficiency vary the most at IMEP Net $=5$ bar. In fact, it appears that the higher level of premixing correlate with efficiency increase, which explains the relatively high indicated efficiency of PRF100.

The variation in efficiency between PRFs starts to drop at IMEP ${ }_{\text {Net }}$ of 10 and 15 bar but still PRF100, with the most premixed RoHR zone, has the highest efficiency. At IMEP Net $=20$ bar, the indicated efficiency becomes insensitive to the octane number of fuel. Thus, it follows that the engine efficiency is independent of fuel at high load and any fuel can be utilized.

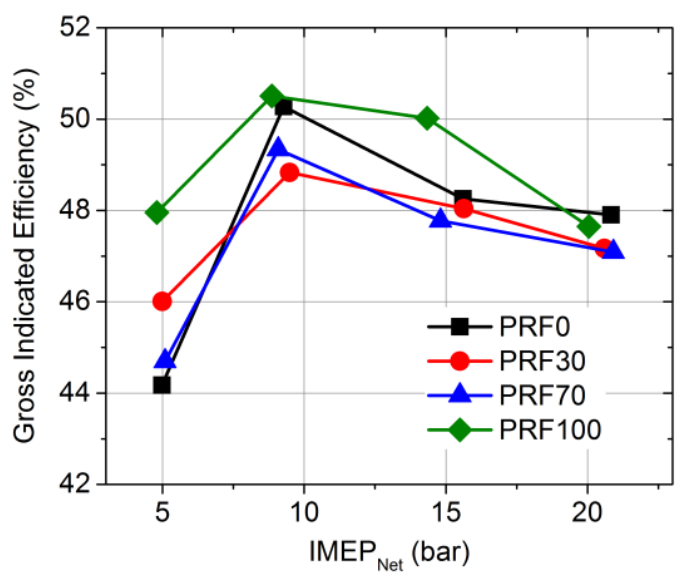

Fig. 7. Gross indicated Efficiency of PRFs at different engine loads

\section{Emissions}

The engine emissions at the constant CA50 analysis are shown in Fig. 8 and 9. NOx emissions increase steadily as a function of load for all the PRFs up to $\mathrm{IMEP}_{\mathrm{Net}}=15$ bar and then suddenly drop. The drop is caused by the SOI retard at IMEP $P_{\text {Net }}=20$ bar which reduces the in-cylinder temperature and hence shrinking probability of NOx formation through the combination of $\mathrm{O}_{2}$ and $\mathrm{N}_{2}$. NOx emissions are similar for all the except for PRF100 at IMEP Net $=5$ bar. The high RoHR of PRF100 causes sharper rise in the incylinder temperature, and so NOx emissions rise.

The concentration of unburned hydrocarbons declines as the load increases due to the rise in temperature. Similar to the NOx emissions, PRFs behave in similar fashion for all the load cases except for PRF100 at $I_{M E P}{ }_{N e t}=5$ bar, where the unburned hydrocarbon emissions are lower. The same aforementioned reasoning for NOx is valid where the higher in-cylinder temperature at PPC mode assist in oxidizing the unburned hydrocarbons.

The $\mathrm{CO}$ emissions for all the PRFs rapidly drops in magnitude for loads beyond IMEP Net $=5$ bar where the engine has diesel-type combustion efficiency. The only outlier with high CO emissions are PRF100 at the lowest load examined herein. This may seem counterintuitive based on the aforementioned discussions where the enhanced mixing of PRF100 causes a rise in the in-cylinder temperature, which should increase the likelihood of $\mathrm{CO}$ to $\mathrm{CO}_{2}$ conversion. For that reason, the experiment was repeated twice at that load point and similar trends were observed. A possible hypothesis for the rise in $\mathrm{CO}$ emissions is the short combustion duration that stands against oxidizing $\mathrm{CO}$.

Similar to all emissions, the largest deviation in soot emission between the studied fuels occurs at IMEP Net = 5 bar. The soot peaks for PRF0 and PRF30 because of their non-premixed burning whereas PRF70 and PRF100 with their enhanced mixing have lower soot emissions. As the load increases, the rail pressure is elevated and so is the level of fuel atomization. This justifies the moderate increase in the soot concentration with the load. Overall, all of the 
emissions of the different PRFs have relatively similar magnitudes at the highest load point, which is yet another indicator of engine's fuel flexibility.
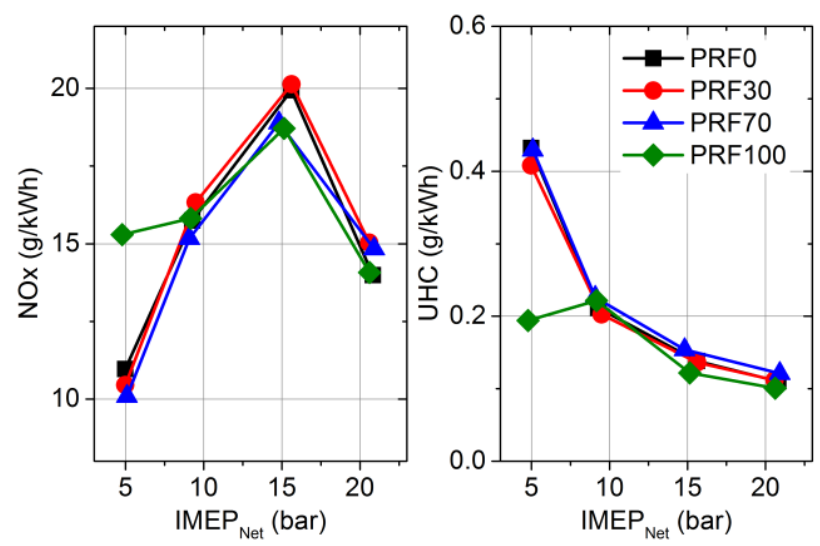

Fig. 8. NOx and unburned hydrocarbon emissions of PRFs at different engine loads.
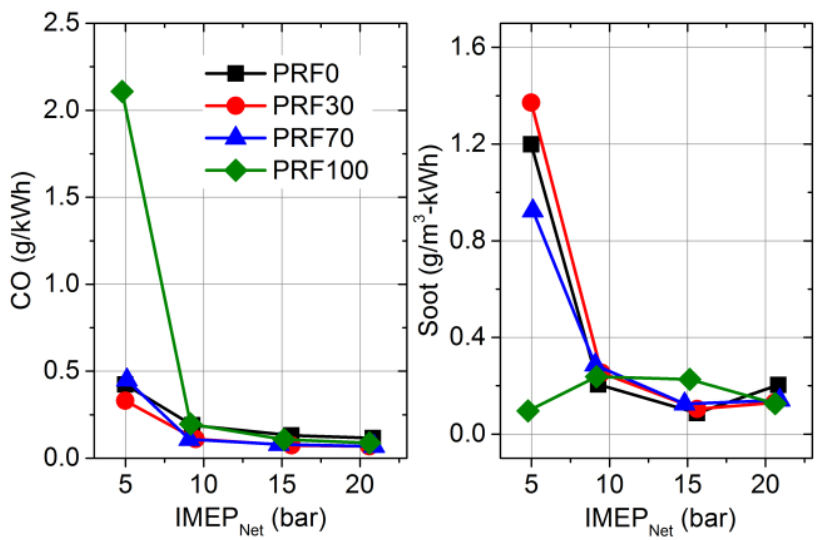

Fig. 9. CO and soot emissions of PRFs at different engine loads.

\section{Constant Start of Injection (SOI)}

\section{In-cylinder Pressure and RoHR}

The motored pressure traces of the cases tested in the constant start of injection analysis is illustrated in Fig. 10. The combustion characteristics of seven fuels with different octane qualities were examined at three load points $P_{\text {intake }}=1.5,2.0$ and 2.5 bar. It is worthwhile to mention that the motored condition at $P_{\text {intake }}=1.5 \mathrm{bar}$ matches the load point of $\operatorname{IMEP}_{\mathrm{Net}}=5$ bar in the constant CA50 analysis. Similarly, the examined condition of $P_{\text {intake }}=2.5$ bar has the same motored condition at IMEP $\mathrm{Net}_{\mathrm{Ne}}=10 \mathrm{bar}$ and $15 \mathrm{bar}$.

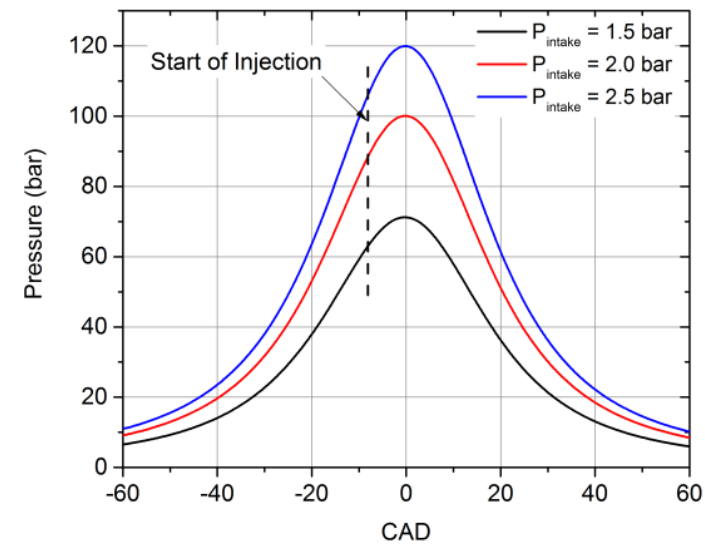

Fig. 10. Motored pressure trace at different intake pressures

The rate of heat release and injector signal for the constant SOI analysis are shown in Fig. 11, 12, and 13. At Pintake $=1.5$ bar (Fig. 11), all the fuels seem to burn in PPC regime where there is sufficient time lag between the SOI and the heat release event, creating sufficient air/fuel mixing. Fuels are releasing heat in an order based on their octane quality. Diesel and nheptane start releasing heat the earliest followed by PRF30. Then, PRF70 and FACE I, where they have the same RON, share the same combustion characteristic. The fuels with the longest mixing durations are gasoline and isooctane. In fact, gasoline burns slightly earlier because of its lower RON of 91 . Out of all the fuels, isooctane is the only one that exhibit two stage heat release with a small low temperature reactivity.

As the intake pressure is elevated to 2 bar (Fig. 12), the fuels with the lowest octane ratings (diesel, PRF0, and PRF30) burn in CI mode. PRF70 and FACE I still follow each other closely where they share the feature of PPC burning regime but with a reduced duration of air/fuel mixing. Even with the variation in their RON values, gasoline and isooctane share the same heat release features. The low temperature heat release of isooctane diminish with the increase in intake pressure. The increase of intake pressure further to 2.5 bar (Fig. 13) causes all the fuels to share the same RoHR characteristics except for isooctane and gasoline. The low octane fuels burn in $\mathrm{Cl}$ mode with a direct correlation in the magnitude of premixed zone of RoHR with the fuel's octane number. Isooctane and gasoline still burn in PPC mode with reduced mixing. Overall, a load region where the engine becomes fully fuel flexible has not been encountered for the constant SOI analysis. At the highest load point tested in this analysis, fuels with RON that spans from 0-70 are the only ones that share similar RoHR characteristics. 
$P_{\text {intake }}=1.5$ bar

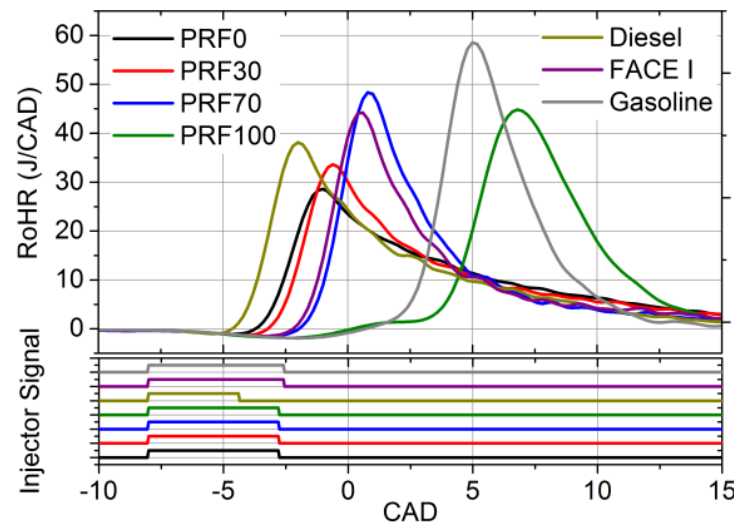

Fig. 11. Rate of heat release $(\mathrm{RoHR})$ with $P_{\text {intake }}=1.5 \mathrm{bar}$ for seven different fuels

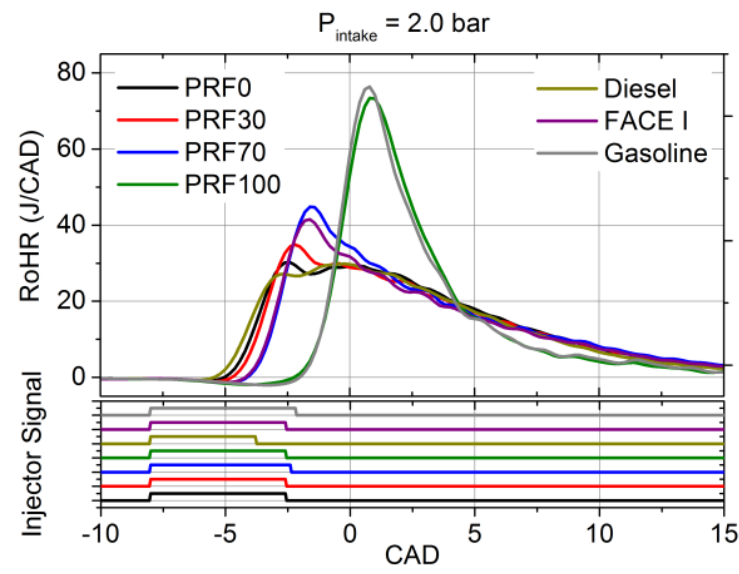

Fig. 12. Rate of heat release $(\mathrm{RoHR})$ with $P_{\text {intake }}=2.0 \mathrm{bar}$ for seven different fuels

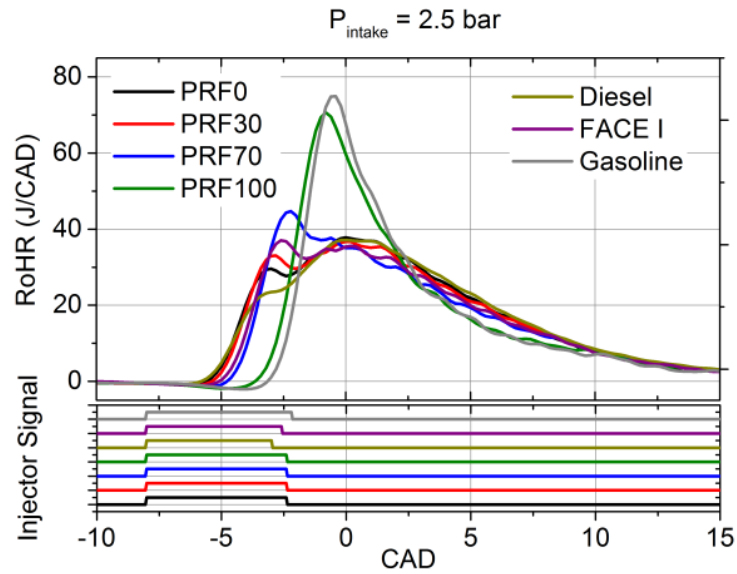

Fig. 13. Rate of heat release $(\mathrm{RoHR})$ with $P_{\text {intake }}=2.5 \mathrm{bar}$ for seven different fuelsl

\section{Engine Load and Combustion Characteristics}

The change of the net indicated mean effective pressure $\left(\right.$ IMEP $\left._{\mathrm{Net}}\right)$ as a function of the intake pressure is shown in Fig. 14. IMEP ${ }_{\text {Net }}$ peaks with a value of 5 bar at the highest inlet pressure tested $\left(P_{\text {intake }}=2.5\right)$, which is quite low compared to the load levels tested at the constant CA50 analysis. This explains the disappearance of load points where the engine becomes fuel flexible.
The ignition delay time and the combustion duration (CA90-CA10) of the seven tested fuels are illustrated in Fig. 15 and 16. The ignition delay time consistently decreases as the intake pressure increases. Higher octane fuels (PRF100 and gasoline) experience the steepest decrease in the ignition delay time. As highlighted in the RoHR graph (Fig. 13), the ignition delay time of the fuels with RON 0-70 have very similar magnitudes with a deviation of 1 CAD.

There is apparent dependency between the burning regime and the combustion duration. Combustion duration increases as function of load for fuels with high octane numbers and vice versa for low octane fuels. The increase in the combustion duration of the high octane fuels are caused by the transitioning from PPC to $\mathrm{Cl}$ mode. There are minor deviations in the combustion duration between the tested fuels at $P_{\text {intake }}$ $=2.5$ bar. Although finding a load point where the engine becomes fully fuel flexible has not been achieved in the constant SOI analysis, it demonstrated the tendency of various fuels (commercial and surrogates) to attain similar combustion characteristics with load elevation.

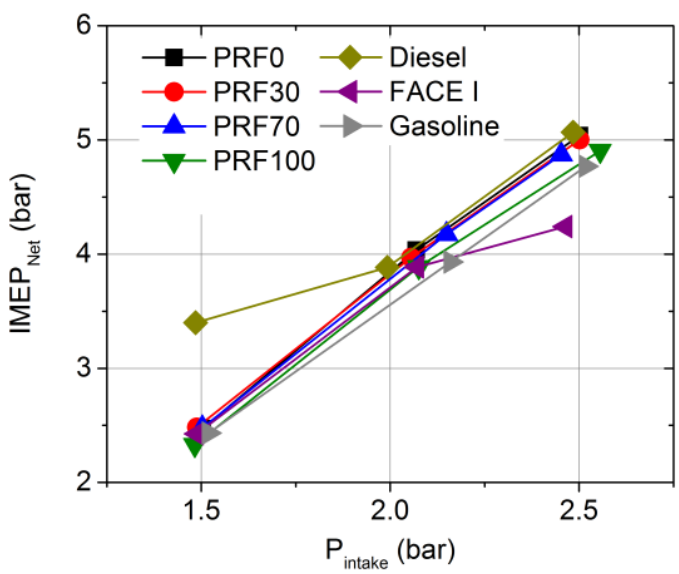

Fig. 14. IMEP $P_{\text {Net }}$ of the seven fuels analyzed in this study at different intake pressures

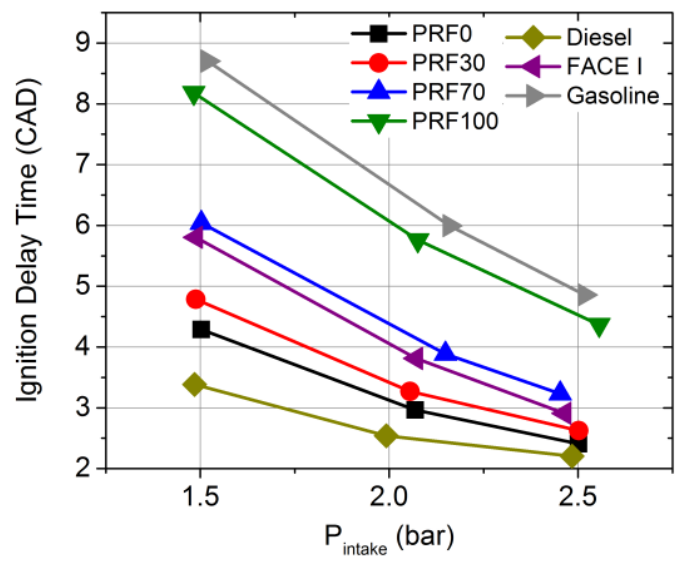

Fig. 15. Ignition delay time of seven fuels at different intake pressures 


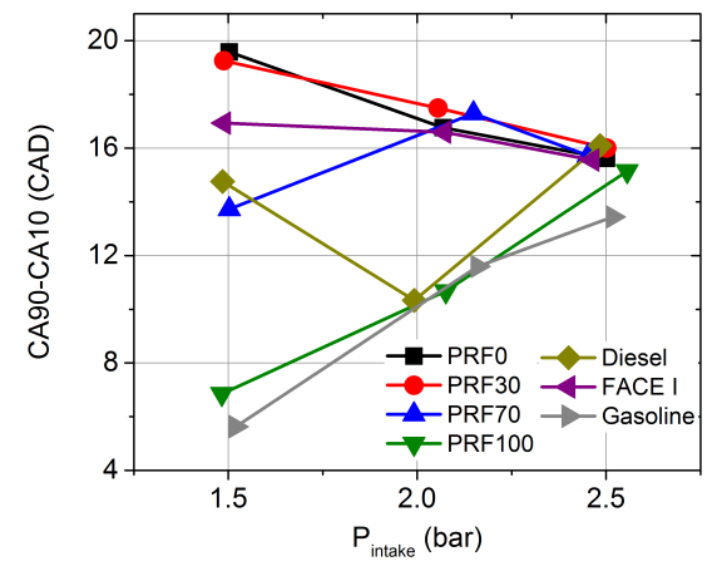

Fig. 16. Combustion duration (CA90-CA10) of seven fuels at different intake pressures

\section{EFFECT OF EXHAUST GAS RECIRCULATION (EGR)}

\section{In-cylinder Pressure and RoHR}

The effect of introducing exhaust gas recirculation (EGR) was studied for the n-heptane and isooctane cases presented in the constant CA50 analysis (Table 3). The in-cylinder pressure trace, rate of heat release (RoHR), and injection duration for the diluted mixtures with EGR at different load points are shown in Fig. 17, 18, 19, and 20. At IMEP Net $=5$ bar, nheptane exhibits burning regime that is driven by diffusion with a slight initial premixed flame at the $0 \%$ EGR case. Upon EGR addition, there is a minor retard in the combustion phasing of $n$-heptane, which slightly enhances the mixing duration. With that, the premixed portion marginally increases. Isooctane, which burns in PPC mode at IMEP ${ }_{\text {Net }}=5$ bar, has higher sensitivity with EGR introduction. There is an apparent retard of the combustion phasing even with minor EGR percentages that causes further mixing enhancement. Feeding the inlet charge with EGR clearly reduces the peak in-cylinder pressure, especially for isooctane.

As the load is elevated to $\mathrm{IMEP}_{\mathrm{Net}}=10$ bar (Fig. 18), isooctane with $0 \% E G R$ maintains its PPC type burning. There is a slight change of slope in the RoHR at 5 CAD aTDC indicating the start of some diffusion based burning. The introduction of EGR suppresses the appearance of non-premixed diffusion burning, transforming the combustion towards PPC mode. The sensitivity of both fuels to EGR becomes lower compared to IMEPNet $=5$ bar case with a minor shift in the RoHR, especially for n-heptane. The peak pressure is dropped for all the cases as EGR is introduced because of the evidential drop in the motored pressure trace. Moving towards the $\mathrm{IMEP}_{\mathrm{Net}}=$ 15 bar case (Fig. 19), EGR has insignificant effect to the RoHR of $n$-heptane. In contrast, EGR has more pronounced effect to isooctane with an apparent increase in the premixed zone. The pressure encounters, similar to the previous cases, a drop because the recycled exhaust has slightly lower pressure.
At the highest load tested (IMEP ${ }_{\text {Net }}=20$ bar) where a fuel-flexible engine was claimed, the EGR effect has been illustrated in Fig. 20. Out of all the parameters examined, EGR introduction has the lowest effect to the RoHR at IMEP Net $=20$ bar. The only noticeable trend is the slight increase in the premixed zone burning of isooctane with high EGR levels. The peak pressure encounters a slight change because of the pressure drop of the recycled exhaust as it travels to the intake. Overall, it is fair to claim that EGR has marginal sensitivity to alter the combustion characteristics at load points where the engine is fuel flexible.

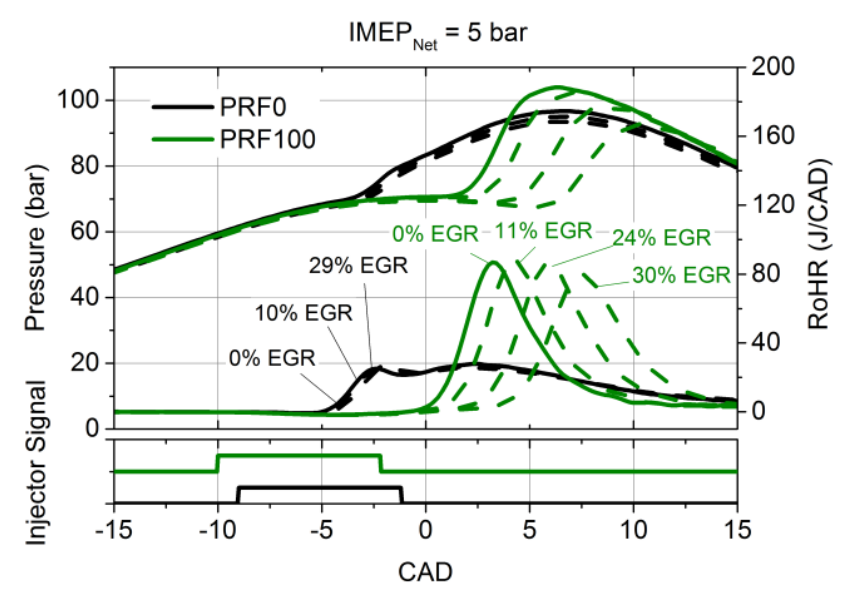

Fig. 17. Pressure, Rate of Heat Release, and injector signal of $n$-heptane and isooctane diluted with EGR at IMEP $P_{\text {Net }}=5$ bar

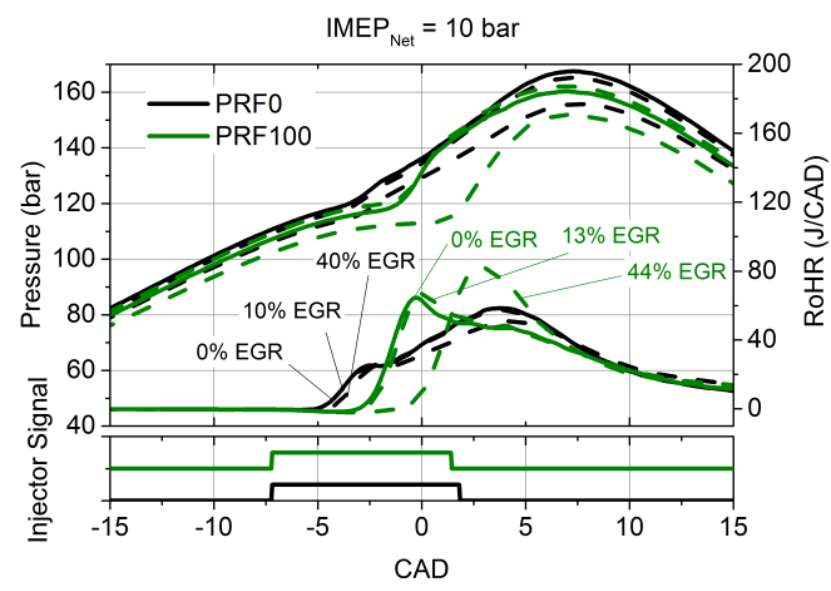

Fig. 18. Pressure, Rate of Heat Release, and injector signal of $n$-heptane and isooctane diluted with EGR at IMEP $P_{\text {Net }}=$ 10 bar 


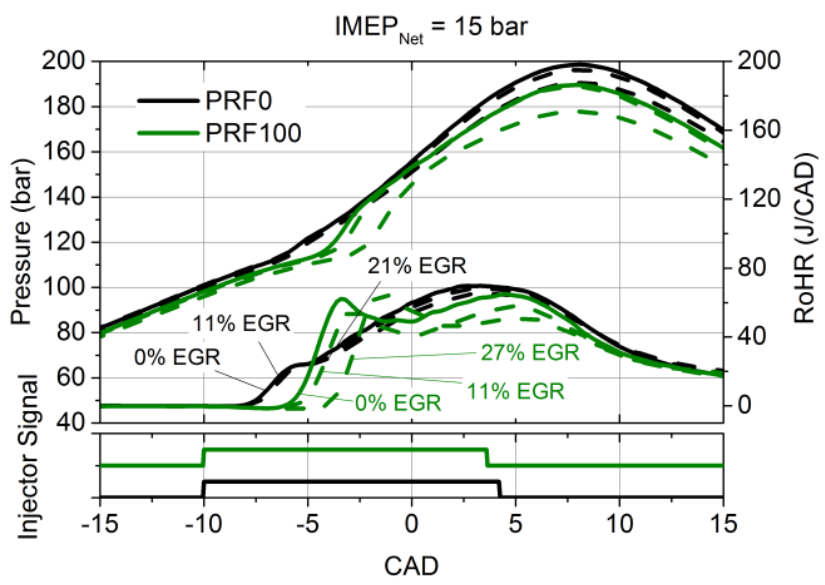

Fig. 19. Pressure, Rate of Heat Release, and injector signal of $n$-heptane and isooctane diluted with EGR at IMEP $P_{\text {Net }}=$ 15 bar

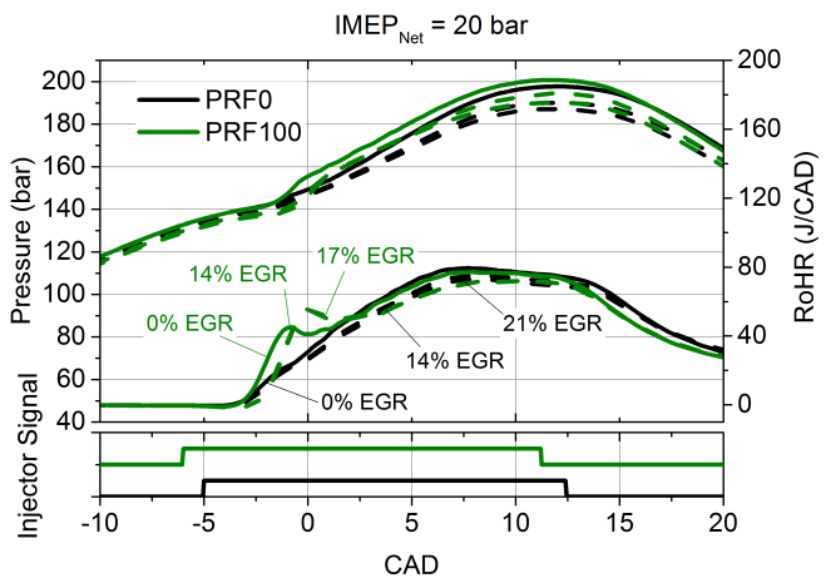

Fig. 20. Pressure, Rate of Heat Release, and injector signal of $n$-heptane and isooctane diluted with $E G R$ at IMEP $P_{\text {Net }}=$ 20 bar

\section{Combustion Characteristics and Efficiency}

The effect of EGR introduction to the ignition delay time of $\mathrm{n}$-heptane and isooctane at the examined loads is shown in Fig. 21. It is apparent that EGR with its cooling and diluting effects reduces the reactivity of the charge. This translates into a consistent increase in the ignition delay time for $\mathrm{n}$-heptane and isooctane at all load points. However, the sensitivity of fuels to EGR varies depending on its octane number and the load level. At low and moderate loads, the change of ignition delay time with EGR has much steeper slope for isooctane in comparison with n-heptane. These are the regions where isooctane have significant premixed zones, in which EGR acts as a reactivity inhibitor. When the burning of the fuel is diffusion driven (i.e. $\mathrm{Cl}$ mode), the inhibition of reactivity with EGR presence becomes more challenging because of the short transient time of the fuel particles. At IMEP ${ }_{\mathrm{Net}}=20 \mathrm{bar}$ where both $\mathrm{n}$-heptane and isooctane burn in $\mathrm{Cl}$ mode, the sensitivity of the fuels with EGR is quite similar.

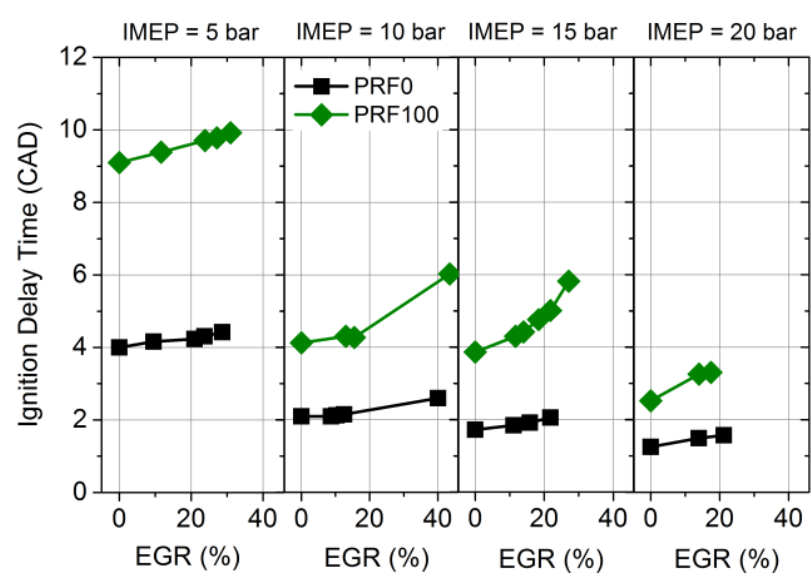

Fig. 21. The effect of EGR on the ignition delay time of PRFO and PRF100 at different loads.

Fig. 22 illustrates the effect that EGR plays on the combustion duration (CA90-CA10) of isooctane and $n$ heptane. The combustion duration of $n$-heptane, which burns in diffusion manner, consistently increases with the elevation in EGR levels. Isooctane follows the same $\mathrm{n}$-heptane trends at conditions where isooctane have minor or significant diffusion portions in its RoHR $\left(\right.$ IMEP $_{\text {Net }}=10,15$, and 20 bar). When isooctane burns purely at PPC mode (IMEP Net $=5$ bar), the combustion duration slightly decreases with EGR addition. A possible justification to this trend is the excessive retard in the combustion phasing away from optimum where the pressure and temperature conditions are becoming moderate.

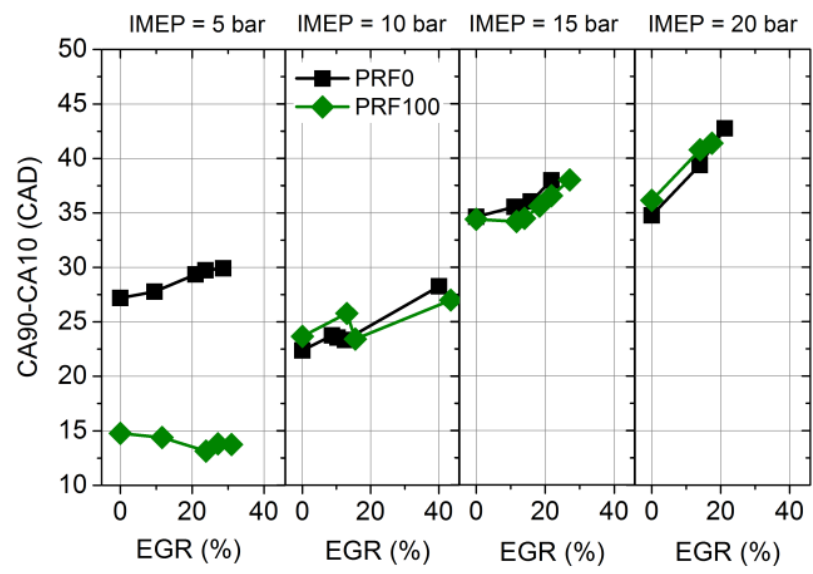

Fig. 22. The effect of EGR on the combustion duration (CA90-CA10) of PRFO and PRF100 at different loads.

A projectile of the change in gross indicated efficiency of $n$-heptane and isooctane with the EGR sweep is shown in Fig. 23. It should be noted that the optimum combustion phasing was at $0 \%$ EGR that is CA50 $=5$ CAD aTDC (except for IMEP ${ }_{\text {Net }}=20$ bar where CA50 was retarded to avoid high peak pressures). Therefore, the shift of ignition delay time with EGR pushes the combustion phasing away from optimum. The aforementioned factor competes with the main advantage that EGR brings, which is the cooling of the in-cylinder charge. This reduces the heat transfer to the cylinder walls, and hence elevates the indicated efficiency. 
At IMEP Net $=5$ bar, the indicated efficiency of isooctane drops steeply with EGR addition because, as demonstrated in Fig. 17, the phase shift is large with EGR addition. Since $n$-heptane experiences only minor shifts away from the desired CA50, the indicated efficiency slightly elevates with the EGR addition due to the reduction of heat transfer.

Similar trends as the aforementioned were observed at $\mathrm{IMEP}_{\mathrm{Net}}=10$ bar and 15 bar. Isooctane, with its larger ignition delay time sensitivity with EGR, suffers from significant efficiency drop with increasing levels of EGR. The drop in efficiency becomes milder and closely follows $n$-heptane at $\mathrm{IMEP}_{\mathrm{Net}}=20$ bar. The difference in efficiency with the EGR sweep between $\mathrm{n}$-heptane and isooctane are within 1\% at the highest load, which is the lowest compared to the other load points. It highlights that even fuels with wide differences in their octane quality burn in diffusion manner at high loads/compression ratio and even EGR cannot make them distinguishable.

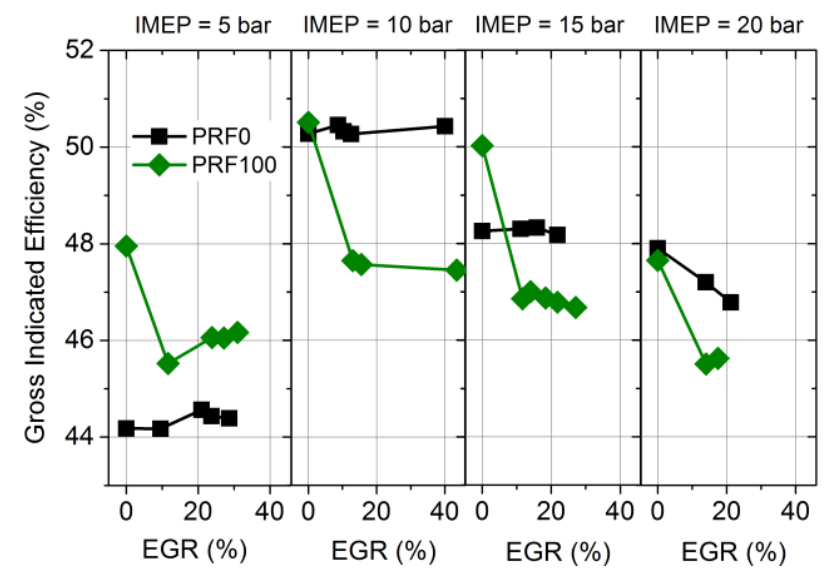

Fig. 23. Gross indicated efficiency of $n$-heptane and isooctane at different EGR levels for engine loads examined in this study.

\section{Emissions}

The emissions associated with the EGR sweep for the cases studied are presented in Fig 24, 25, 26, and 27. NOx emissions were as expected since the cooled EGR reduces average in-cylinder temperature. This reduces the likelihood of producing thermal NOx. NOx levels associated with $\mathrm{n}$-heptane and isooctane combustion tie each other at the high loads. High levels of $\mathrm{CO}$ emissions are only observed for isooctane at IMEP ${ }_{\text {Net }}=5$ bar. At this load point, isooctane burn in PPC mode with very short combustion duration, which stands against the $\mathrm{CO}$ to $\mathrm{CO}_{2}$ conversion. The increase of EGR at this load point worsens the CO emissions as the combustion phasing is largely shifted from the optimum point (illustrated in Fig. 17). This causes a reduction in the combustion efficiency and thus, an increase in the $\mathrm{CO}$ emissions. At loads beyond $\mathrm{IMEP}_{\mathrm{Net}}=5 \mathrm{bar}$, the $\mathrm{CO}$ emission has low basis and it moderately increases with EGR due to the cooling effect.

There is not any major trend to be reported in the unburned hydrocarbon emissions other than the increase in its levels with isooctane at IMEP $P_{\text {Net }}=5$ bar. As discussed in the $\mathrm{CO}$ emissions, this occurs because of the reduction in combustion efficiency of isooctane at this load point. The unburned hydrocarbons overall reduces as a function of load and both fuels follow similar trends at high loads.

At IMEP $_{\text {Net }}=5$ bar, $n$-heptane experiences high soot levels because it burns in a diffusion manner and the fuel is injected at low pressure. The soot level of $n$ heptane increases with EGR as the cooling effect stands against post oxidation of soot. Isooctane with its enhanced mixing at IMEP $\mathrm{Net}_{\mathrm{Ne}}=5$ bar has low soot levels even with EGR. Moving towards higher loads $\left(\right.$ IMEP $_{\text {Net }}=10-20$ bar), the soot levels overall decrease but the high levels of EGR elevates the concentrations of soot. This is again attributed to the inhibition of the soot oxidation mechanism because of the decrease in the average cylinder temperature. Overall, the emissions of isooctane and n-heptane combustion at high loads follow similar trends even with the EGR addition.

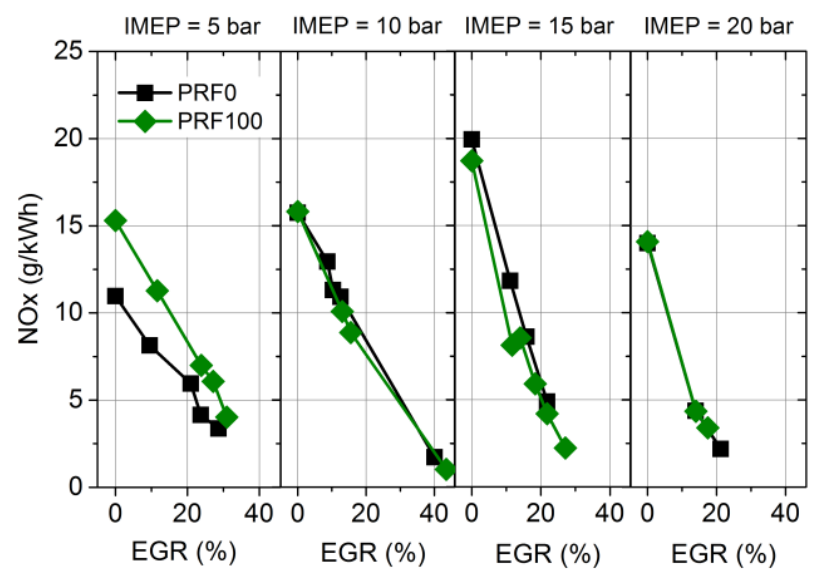

Fig. 24. NOx emissions associated with EGR at different loads.

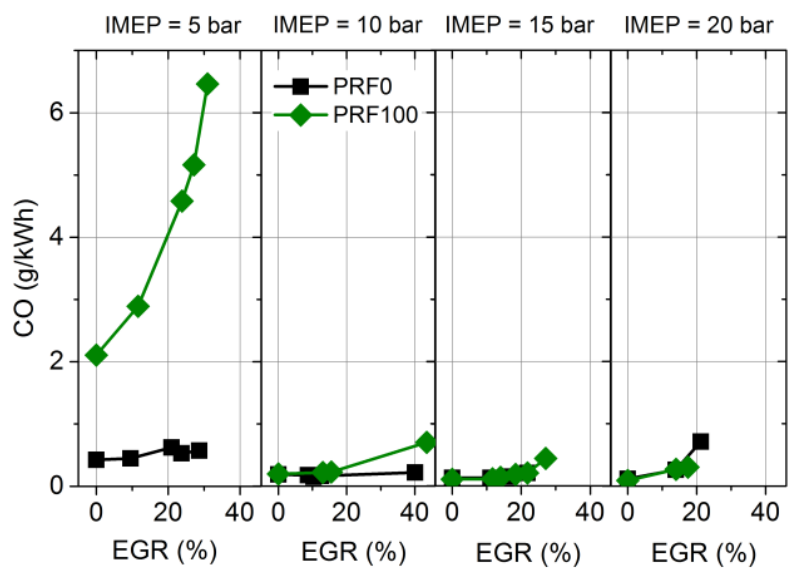

Fig. 25. CO emissions associated with EGR at different loads. 


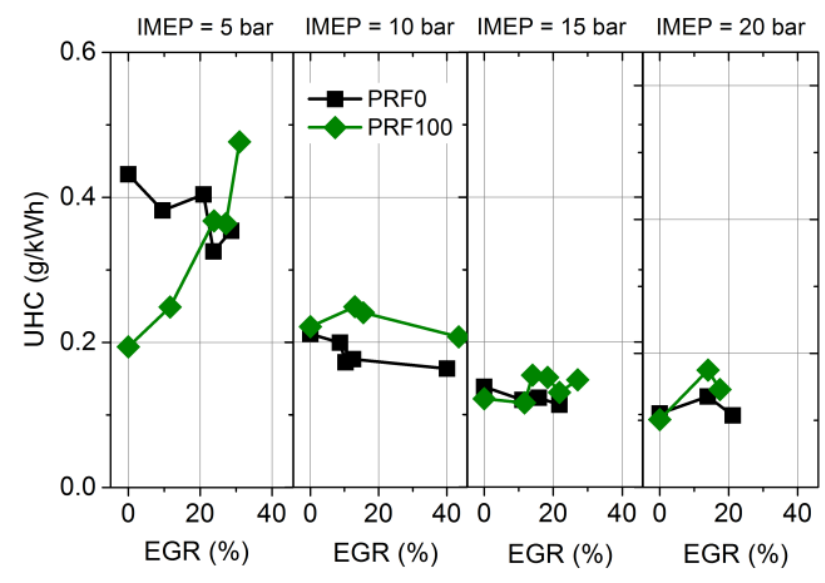

Fig. 26. Unburned hydrocarbon emissions associated with EGR at different loads.

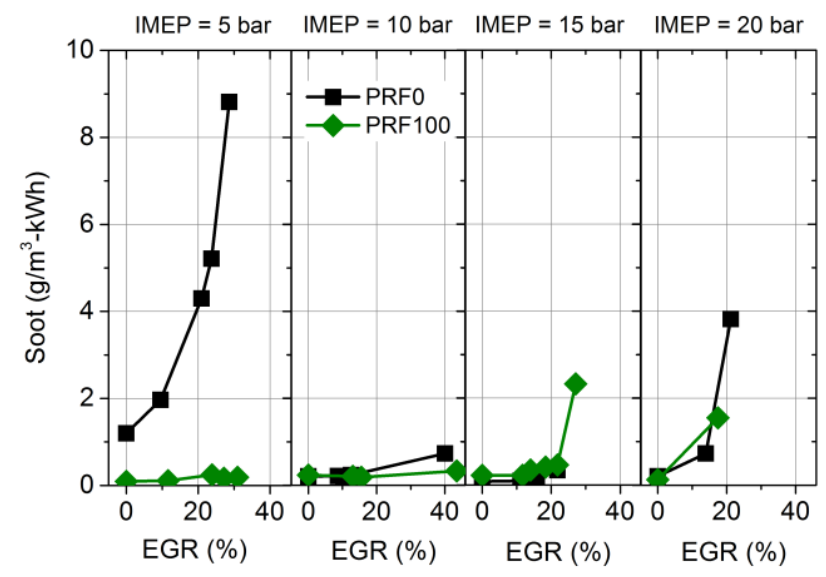

Fig. 27. Soot emissions associated with EGR at different loads.

\section{CONCLUSIONS}

A conventional heavy duty diesel engine was operated with fuels having a very wide range of auto-ignition characteristics. Fuels that represents the octane scale were selected, namely n-heptane and iso-octane and their mixtures. Commercial gasoline, diesel and naphtha were also tested.

- At an engine load of 20 IMEP, all mixtures of iso-octane and $\mathrm{n}$-heptane gave the same combustion process and hence also the same efficiency and emission characteristics.

- The constant SOI analysis demonstrated the tendency of real fuels having multi-component mixtures to share similar behavior as the isooctane/n-heptane mixtures with load elevation.

- At 2.5 bar intake pressure, all fuels having an octane number below 70 behaved the same. The 100 octane iso-octane and the $91 \mathrm{RON}$ gasoline started to demonstrate more premixed combustion and gave a slight shift in combustion characteristics.

- At 10 bar IMEP, a larger separation of fuels have been reported with the high octane fuels are becoming no longer diffusion controlled combustion to large extent. A clear improvement in indicated efficiency could be noted with the shorter burn duration of the partially premixed type of combustion as compared to n-heptane.

- At 5 bar IMEP, the fuels have very different behavior and the combustion mode range from fully premixed for fuels with 70-100 RON to diffusion influenced for the 0-70 RON fuels.

- Emissions of $\mathrm{NOx}, \mathrm{HC}, \mathrm{CO}$, and soot all were the same for all fuels when the combustion was diffusion controlled. The high octane fuels showed increase in $\mathrm{HC}$ and $\mathrm{CO}$ at low load as the fuel exposure to high temperatures was not long enough to achieve complete combustion.

- The response to EGR was the same for nheptane and iso-octane at high loads. At low loads the diffusion controlled n-heptane gave less THC with introduction of EGR, whereas THC was increased with iso-octane. Soot was much higher for n-heptane than iso-octane at low load and increased much with EGR.

- The results show that diesel engine operated at mid to high load can use any fuel. It does not matter if the octane number is 0 or 100 . Hence, the diesel engine can be considered totally fuel flexible, at least when considering the fuel auto ignition properties.

- If the partially premixed type of combustion, PPC, is desired to attain higher efficiency, low octane fuels have very narrow range of operation at high compression ratio. In addition, the high octane fuels can be challenging to operate at maximum load where the combustion transitions to conventional $\mathrm{Cl}$ combustion.

\section{REFERENCES}

1. British Petroleum, "BP energy outlook energy 2017," BP Stat. Rev. World Energy, 2017.

2. Sims, R., Schaeffer, R., Creutzig, F., CruzNúñez, X., D’agosto, M., Dimitriu, D. et al., "Transport Climate Change 2014: Mitigation of Climate Change. Contribution of Working Group III to the Fifth Assessment Report of the Intergovernmental Panel on Climate Change ed O Edenhofer et al.," Cambridge University Press, 2014.

3. International Energy Agency (IEA), "CO2 Emissions From Fuel Combustion. Highlights 2015," International Energy Agency Paris, 2015.

4. Kalghatgi, G., "Is it really the end of internal combustion engines and petroleum in transport?, " Applied Energy 225: 965-974, 2018, doi:10.1016/j.apenergy.2018.05.076.

5. Opec, "2013 World Oil Outlook, "OPEC Secretariat Austria ISBN 978-3-9502722-6-0, 
2013.

6. Conti, J., Holtberg, P., Diefenderfer, J., LaRose, A., Turnure, J. T., and Westfall, L., "International energy outlook 2016 with projections to 2040," USDOE Energy Information Administration (EIA), 2016.

7. Exxon Mobil, "The Outlook for Energy: A View to 2040," Exxon Mobil Corporation Texas, 2016.

8. Gadonneix, P., Sambo, A., Tie'nan, L., Choudhury, A. R., Teyssen, J., Lleras, J. A. V. et al., "Global Transport Scenarios 2050," World Energy Council, 2011.

9. Kalghatgi, G., "Developments in internal combustion engines and implications for combustion science and future transport fuels," Proceedings of the Combustion Institute 35: 101-115, 2015, doi: 10.1016/i.proci.2014.10.002.

10. Kalghatgi, G., "The outlook for fuels for internal combustion engines," International Journal of Engine Research 15: 383-398, 2014, doi: 10.1177/1468087414526189.

11. Kalghatgi, G., and Johansson, B., "Gasoline compression ignition approach to efficient, clean and affordable future engines," Proceedings of the Institution of Mechanical Engineers, Part D: Journal of Automobile Engineering 232(1): 118-138, 2018, doi: 10.1177/0954407017694275.

12. Kalghatgi, G. T., Risberg, P., and Ångström, H. E., "Advantages of fuels with high resistance to auto-ignition in late-injection, lowtemperature, compression ignition combustion," SAE Technical Paper 2006-013385, 2006, doi:10.4271/2006-01-3385.

13. Chang, J., Kalghatgi, G., Amer, A., and Viollet, $Y$., "Enabling high efficiency direct injection engine with naphtha fuel through partially premixed charge compression ignition combustion," SAE Technical Paper 2012-010677, 2012, doi:10.4271/2012-01-0677.

14. Hildingsson, L., Kalghatgi, G., Tait, N., Johansson, B., and Harrison, A., "Fuel octane effects in the partially premixed combustion regime in compression ignition engines," SAE Technical Paper 2009-01-2648, 2009, doi: 10.4271/2009-01-2648.

15. Manente, V., Zander, C. G., Johansson, B., Tunestal, P., and Cannella, W., "An advanced internal combustion engine concept for low emissions and high efficiency from idle to max load using gasoline partially premixed combustion," SAE Technical Paper 2010-012198, 2010, doi:10.4271/2010-01-2198.

16. Christensen, M., Hultqvist, A., and Johansson, B., "Demonstrating the multi fuel capability of a homogeneous charge compression ignition engine with variable compression ratio," SAE Transactions: Journal of Engines 108(3): 2099-2113, 1999, doi: 10.4271/1999-01-3679.

17. Wang, S., de Visser, A. J. M., and Somers, L. M. T., "Study on low temperature and conventional diesel combustion with fuel blends of RON70," 7th European Combustion Meeting Budapest, 2015.

18. Paz, J., Staaden, D., and Kokjohn, S.,
"Gasoline compression ignition operation of a heavy-duty engine at high load," SAE Technical Paper 2018-01-0898, 2018, doi: 10.4271/2018-01-0898.

19. Lam, N., Tuner, M., Tunestal, P., Andersson, A., Lundgren, S., and Johansson, B., "Double compression expansion engine concepts: a path to high efficiency," SAE International Journal of Engines, 8(4): 1562-1578, 2015, doi: $10.4271 / 2015-01-1260$.

20. Shankar, V. S. B., Johansson, B., and Andersson, A., "Double compression expansion engine: a parametric study on a high-efficiency engine concept," SAE Technical Paper 2018-01-0890, 2018, doi: 10.4271/2018-01-0890.

21. Lam, N., Andersson, A., and Tunestal, P., "Double Compression Expansion Engine Concepts: Efficiency Analysis over a Load Range, ", SAE Technical Paper 2018-01-0886, 2018, doi: 10.4271/2018-01-0886.

22. Nyrenstedt, G., Alturkestani, T., Im, H., and Johansson, B., "CFD Study of Heat Transfer Reduction Using Multiple Injectors in a DCEE Concept," SAE Technical Paper 2019-010070, 2019, doi: 10.4271/2019-01-0070.

23. Meek, G. A., Williams, R., Thornton, D., Knapp, P., and Cosser, S., "F2E-Ultra High Pressure Distributed Pump Common Rail System," SAE Technical Paper 2014-01-1440, 2014, doi: 10.4271/2014-01-1440.

24. ASTM International, "Standard Test Method for Research Octane Number of Spark-Ignition Engine Fuel," ASTM D2699-18a, 2018, doi: 10.1520/D2699-18A.

25. ASTM International, "Standard Test Method for Motor Octane Number of Spark-Ignition Engine Fuel," ASTM D2700-18a, 2018, doi: 10.1520/D2700-18A.

26. Cannella, W., Foster, M., Gunter, G., and Leppard, W., "FACE gasolines and blends with ethanol: detailed characterization of physical and chemical properties," CRC Report No AVFL-24, 2014.

27. Leermakers, C. A. J., Bakker, P. C., Nijssen, B. C. W., Somers, L. M. T., and Johansson, B. $H$., "Low octane fuel composition effects on the load range capability of partially premixed combustion," Fuel 135: 210-222, 2014, doi: 10.1016/i.fuel.2014.06.04.

\section{CONTACT INFORMATION}

Abdullah S. AlRamadan

PhD Student

Clean Combustion Research Center (CCRC)

King Abdullah University of Science and Technology (KAUST)

Thuwal, Saudi Arabia

Email: Abdullah.alramadan@kaust.edu.sa

Phone: +966 505833244 


\section{DEFINITIONS/ABBREVIATIONS}

CAD

CA50

EGR

FACE

GCI

GHG

$\mathrm{HCCl}$

IC

IDT

IMEP ${ }_{\text {Gross }}$

IMEP $_{\text {Net }}$

MON

PPC

PRF

RoHR

RON

SOHC

sol

TDC
Crank angle degree

CAD at which $50 \%$ of the heat is released

Exhaust gas recirculation

Fuel for advanced combustion engines

Gasoline compression ignition

Greenhouse gases

Homogenous charge compression ignition

Internal combustion

Ignition delay time

Gross indicated mean effective pressure

Net indicated mean

effective pressure

Motor octane number

Partially premixed combustion

Primary reference fuel

Rate of heat release

Research octane number

Single overhead camshaft

Start of injection

Top dead center 
